\title{
Area Classification of Surrounding Parking Facility Based on Land Use Functionality
}

\author{
Jingjing Yin, Yulong He, Xiaoduan Sun \\ College of Metropolitan Transportation, Beijing University of Technology, Beijing, China \\ Email: yinjingjing0323@163.com, ylhe@bjut.edu.cn, xsun@louisiana.edu
}

Received 7 June 2016; accepted 11 July 2016; published 14 July 2016

Copyright (C) 2016 by authors and Scientific Research Publishing Inc.

This work is licensed under the Creative Commons Attribution International License (CC BY). http://creativecommons.org/licenses/by/4.0/

c. (i) Open Access

\section{Abstract}

The different land use surrounding parking facility has significant impact on parking behavior. This paper studies the functional classification of land use surrounding parking facility, which is fundamentally important for in-depth research on parking behavior. 37 parking facilities located between the second and sixth ring roadway in Beijing were selected for this study. Based on the surveys conducted at these parking facilities, various parking behavior were analyzed, based on which the scope of the different parking was determined. The information on location, land use characteristics, public transport, the surrounding parking situations are collected for each investigated parking facility. Applying the SPSS clustering method, the threshold was developed for the classification. Totally, five categories are proposed for the land use functionality surrounding parking facility as the results of this study.

\section{Keywords}

Parking Lot, Functionality, Land Use, SPSS, Classification

\section{Introduction}

The different land use surrounding parking facility has significant impact on parking behavior. The different land use surrounding parking facility can produce different parking demand, and it also can make the parking behavior significantly different.

Song Wei divides the peripheral districts of project according to different functions taking the premise of commercial location, and established the related mathematical model, and puts forward a method to identify the traffic impact area based on commercial location, travel time and urban breaking — point theory [1]; Wang Shuwei, based on the passenger investigation, presents a method to determine the catchment area with consideration of the grid type road network characteristics; with the introduction of the Thiessen po- 
lygon, it solves the coincidence problem of catchment areas, and then presents a delineating method for potential catchment area [2]; Miao lixin said that the land use, the economic factors, and the traffic conditions should be considered to arrange parking facilities, and establish corresponding policies and strategies to solve the problem of parking [3]; Huang Rongqing said that the function of a certain zone within an area depends on the location, resources, geographical and natural environment, historic development as well as its functionality in the area [4]; Meng Fanru researched the type of function structure and the layout characteristics of functions, which is about the core area of high-speed railway station. He researched it in a systematic way by using comparative analysis and ease study, and investigated the pattern of space use and development intensity of the core area of high-speed railway station [5]; Wu yang pointed the characteristics of fringe area function, the principles for identifying types of urban fringe, and evaluated its functions [6].

At present, for the research of the land use surrounding the parking facility, basically in the level of qualitative research, the basis of classification is not clear, and the classification is simple. Studying the functional classification of land use is the premise and foundation for in-depth research on parking behavior, and the paper is based on the international and domestic researches. In view of the domestic development trend of the parking area function, carrying on the quantitative research about the division of the area surrounding the parking lot, the related basis and specific recommendations of the classification are put forward, hoping to provide reference for other cities.

\section{Survey Scheme}

37 parking facilities located between the second and sixth ring roadway in Beijing were selected for this study. The properties of the parking facilities include commercial, office, residential, Culture and sports, hospitals, and mix.

\subsection{Determining the Influenced Scope of the Parking Lot}

From the parking lot to the destination all the completion of this process is to be with man's activities for material carrier, it means the people acceptable range on foot. Therefore, the influence range around the parking lot can be determined according to the suitable walking distance.

In this paper, through the way of the actual distribution-recycling questionnaire, 3475 questionnaires were gotten, and these questionnaires are from 140 parking lots. Get the time of drivers from the parking lot walking to the destination, as shown in Figure 1, Select the 90\% walking time conversion into distance, and it is the influence of the parking lot.

The $90 \%$ of the walking time distance with different properties of parking facilities [7], the hospital is about less than 6 minutes, the mix is less than 7 minutes, the office and commercial are less than 7.5 minutes, the culture and sports is about less than 11 minutes, the residential is about less than 15 minutes.

Specified in the "Highway capacity Manual" [8]: The pedestrian walking speed depends on the pedestrian in the elderly (above 65 years old). If $0 \% \sim 20 \%$ of the pedestrian is the elderly, to calculate the pavement, the pedestrian walking speed can use $1.2 \mathrm{~m} / \mathrm{s}$; If more than $20 \%$ of the pedestrian is the elderly, the pedestrian walking speed can use $1 \mathrm{~m} / \mathrm{s}$. This paper, according to data from the survey, the percent of the pedestrians higher than 60 years old is $11 \%$, obviously, the percent of the pedestrians higher than 65 years old will be more than $11 \%$, So the pedestrian walking speed can use $1.2 \mathrm{~m} / \mathrm{s}$. So the formula of $90 \%$ total walking distance is time $(\mathrm{min}) \times 60 \times$ 1.2, obtained by calculations, the influence of the parking lot of commercial, office, residential, culture and sports, hospital, mixed [9], is 540 meters, 540 meters, 1080 meters, 792 meters, 432 meters, 504 meters respectively [10].

\subsection{The Data Investigation and Sorting Surrounding Parking Facility}

The basic information of the 37 parking facilities, and the public traffic surrounding parking facility, the land use, the location, the distribution of the parking facilities are included in the survey data. The scope of the surrounding area specified according to the previous section. According to the research results at home and abroad, this paper has chosen six indexes, from the public traffic, land utilization, parking location, parking lot, etc., the meaning of each index and quantitative methods [11] are shown in Table 1. 


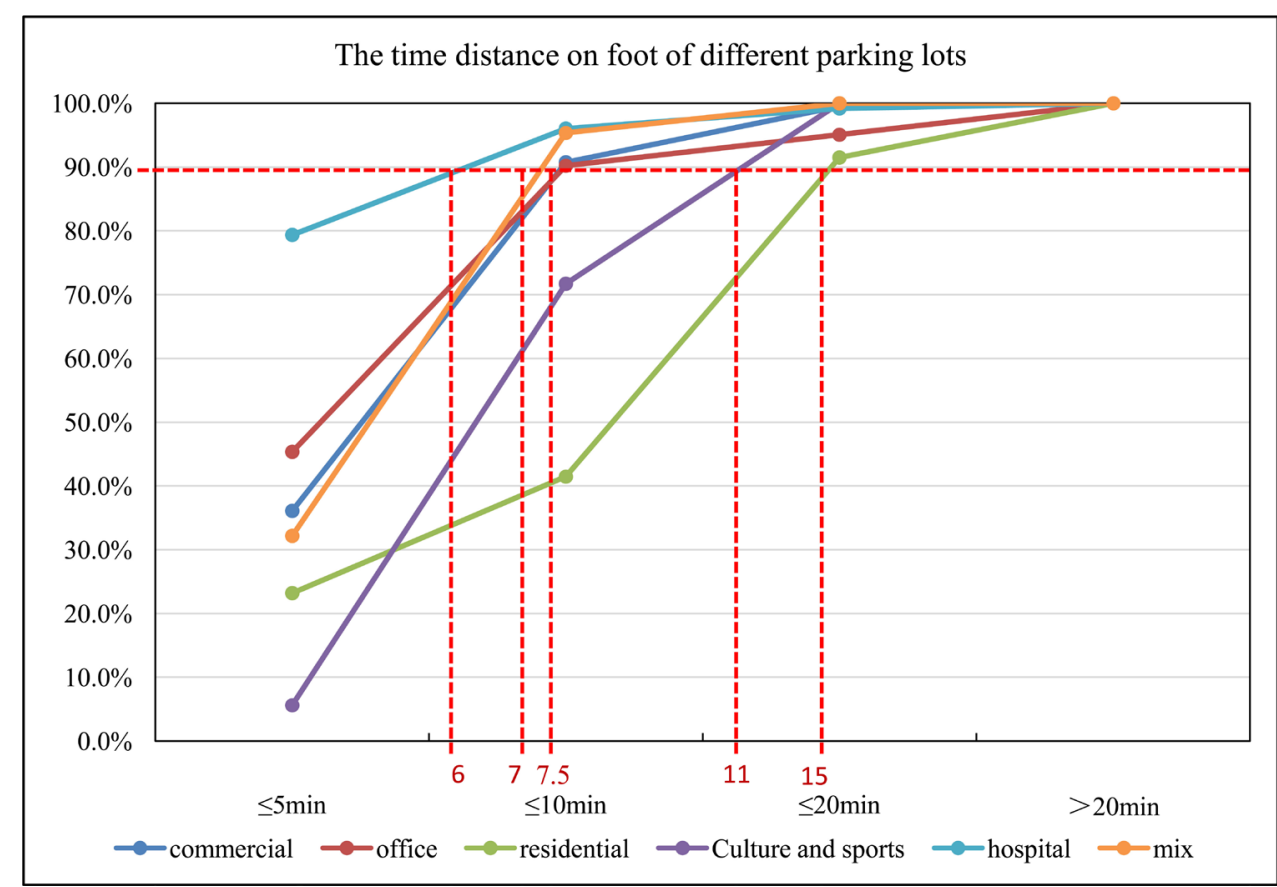

Figure 1. The time distance on foot of different parking facilities.

Table 1. Evaluation indexes of area surrounding parking facilities.

\begin{tabular}{cccl}
\hline Number & Index name & Index sign & \multicolumn{1}{c}{ Index meaning or quantitative methods } \\
1 & Nature of the parking lot & $X_{1}$ & $\begin{array}{l}\text { The properties of the main building which the parking service, if it is a public } \\
\text { parking lot, its nature is mixed }\end{array}$ \\
2 & Bus traffic & $X_{2}$ & The number of bus lines surrounding the parking lot \\
3 & Subway traffic & $X_{3}$ & The number of subway lines surrounding the parking lot \\
4 & Location & $X_{4}$ & The linear distance from the central city to the parking lot, the unit is km \\
5 & Number of parking spaces & $X_{5}$ & The actual number of parking Spaces \\
6 & Distribution of the parking lot & $X_{6}$ & Number of other parking facilities around within the scope of influence \\
\hline
\end{tabular}

We obtain the basic data for the further research from the data of the 37 parking facilities through investigating and normalizing the data of the six indicators. They are the six initial index variables.

\section{The Classification of the Area Surrounding Parking Facility}

\subsection{Clustering Analysis}

Using a two-stage clustering method to categorize the parking lot, using SPSS software, parking lot can be divided into 5 groups, specific classification is as follows:

Class 1: parking lot: 1, 2, 4, 5, 7, 21, 26, 27, 32, 33, a total of 10.

Class 2: parking lot: $28,34,35$, a total of 3 .

Class 3: parking lot: 3, 8, 9, 10, 11, 16, 17, 20, 22, 24, 29, a total of 11.

Class 4: parking lot: 30, 36, a total of 2.

Class 5: parking lot: $6,12,13,14,15,18,19,23,25,31,37$, a total of 11.

According to the initial investigation results and the development intensity of the parking facilities, determined the value of five types, shown in Table 2, the value will be used later.

\subsection{Factor Analysis}

Using the factor analysis function of SPSS, analyze the normalization of data, to eliminate the correlation be- 
tween the variables, reduce the number of variables, after receive the transformation principal components, shown in Table 3.

As you can see by the above form, the cumulative contribution rate of factor $1 \sim 4$ was $89.847 \%$, more than $85 \%$, therefore the four factors can be used instead of the initial variables, four factors were expressed in $Z_{1} \sim Z_{4}$, and the factor score coefficient is shown in Table 4.

Linear correlation analysis the assignment results of the parking lot development intensity and principal component, the results as shown in Table 5.

As you can see from Table 5 , the significance level of $Z_{4}$ is 0.509 , and it shows that $Z_{4}$ has significantly lower levels. Selecting Z1/Z2/Z3 as the independent variables with significantly higher levels, and then we can get the $Y$ equation which is about the development strength of the parking lot, as shown below:

$$
Y=-0.765 Z_{1}-0.389 Z_{2}+0.473 Z_{3}+4.595
$$

The $Z_{1}$, as well as $Z_{2}$ and $Z_{3}$, is a linear combination of the initial variable, according to Table 4 .

Table 2. Assignment of clustering results.

\begin{tabular}{cccccc}
\hline Clustering results & Class 1 & Class 2 & Class 3 & Class 4 & Class 5 \\
Assignment results & 5 & 2 & 3 & 1 & 4 \\
\hline
\end{tabular}

Table 3. Total variance explained.

\begin{tabular}{|c|c|c|c|c|c|c|c|c|c|}
\hline \multirow{2}{*}{ Component } & \multicolumn{3}{|c|}{ Initial Eigenvalues } & \multicolumn{3}{|c|}{ Extraction sums of squared loadings } & \multicolumn{3}{|c|}{ Rotation sums of squared loadings } \\
\hline & Total & $\%$ of Variance & Cumulative \% & & Total & $\%$ of Variance & Cumulative \% & & Total \\
\hline 1 & 2.534 & 42.241 & 42.241 & 2.245 & 37.417 & 37.417 & 1.521 & 25.346 & 25.346 \\
\hline 2 & 1.485 & 24.758 & 66.999 & 1.235 & 20.575 & 57.993 & 1.162 & 19.362 & 44.707 \\
\hline 3 & 0.696 & 11.602 & 78.601 & 0.490 & 8.168 & 66.160 & 1.099 & 18.311 & 63.019 \\
\hline 4 & 0.675 & 11.246 & 89.847 & 0.066 & 1.106 & 67.266 & 0.255 & 4.247 & 67.266 \\
\hline 5 & 0.438 & 7.299 & 97.147 & & & & & & \\
\hline 6 & 0.171 & 2.853 & 100.000 & & & & & & \\
\hline
\end{tabular}

Table 4. Component score coefficient matrix.

\begin{tabular}{ccccc}
\hline & & \multicolumn{3}{c}{ Component } \\
\cline { 2 - 5 } \\
\cline { 2 - 6 } & $Z_{1}$ & $Z_{2}$ & $Z_{3}$ & 0.014 \\
$\mathrm{X}_{2}$ & -0.043 & -0.044 & 0.108 & -0.081 \\
$\mathrm{X}_{3}$ & 0.354 & 0.279 & -0.349 & 0.068 \\
$\mathrm{X}_{4}$ & 0.677 & -0.322 & 0.167 & -0.130 \\
$\mathrm{X}_{5}$ & 0.129 & 0.106 & 0.793 & 0.370 \\
$\mathrm{X}_{6}$ & -0.010 & -0.014 & 0.003 & 0.129 \\
\hline
\end{tabular}

Table 5. Coefficients.

\begin{tabular}{|c|c|c|c|c|c|}
\hline \multirow{2}{*}{ Model } & \multicolumn{2}{|c|}{ Unstandardized coefficients } & \multirow{2}{*}{$\begin{array}{c}\text { Standardized coefficients } \\
\text { Beta }\end{array}$} & \multirow{2}{*}{$\mathrm{t}$} & \multirow{2}{*}{ Sig. } \\
\hline & B & Std. Error & & & \\
\hline (Constant) & 4.595 & 0.169 & & 27.202 & 0.000 \\
\hline$Z_{1}$ & -0.765 & 0.202 & -0.545 & -3.784 & 0.001 \\
\hline$Z_{2}$ & -0.389 & 0.209 & -0.271 & -1.861 & 0.042 \\
\hline$Z_{3}$ & 0.473 & 0.198 & 0.339 & 2.393 & 0.023 \\
\hline$Z_{4}$ & 0.339 & 0.508 & 0.107 & 0.668 & 0.509 \\
\hline
\end{tabular}


Table 6. Category classification.

\begin{tabular}{cc}
\hline Classification & Y range \\
I & $<4.4$ \\
II & $4.4 \sim 4.5$ \\
III & $4.5 \sim 4.6$ \\
IV & $4.6 \sim 4.7$ \\
V & $>4.7$ \\
\hline & \\
$Z_{1}=-0.043 X_{1}+0.354 X_{2}+0.667 X_{3}+0.129 X_{4}-0.010 X_{5}-0.239 X_{6}$ \\
$Z_{2}=-0.044 X_{1}+0.279 X_{2}-0.322 X_{3}+0.106 X_{4}-0.014 X_{5}+0.764 X_{6}$ \\
$Z_{3}=0.108 X_{1}-0.349 X_{2}+0.167 X_{3}+0.793 X_{4}+0.003 X_{5}-0.082 X_{6}$
\end{tabular}

Combined with formula (1) and formula (2) it is concluded that $Y$ about initial variable equation is as follows:

$$
Y=0.106 X_{1}-0.572 X_{2}-0.291 X_{3}+0.191 X_{4}+0.140 X_{5}-0.109 X_{6}+4.595 \text {. }
$$

Put the normalized data into the basis of the above equations, get the finally division standard of the surrounding area of parking lot, according to the development intensity, it is divided into classification $\mathrm{I} \sim \mathrm{V}$ from small to large, as shown in Table 6.

\section{Conclusions}

This paper investigated the 37 parking facilities in Beijing, and chosen six indexes, including nature of the parking lot, bus traffic, subway traffic, location, number of parking spaces and distribution of the parking lot. Through those, area of surrounding parking facility was classified based on land use functionality. This paper first, through the questionnaire survey and analysis, determined the influence area of different nature of the parking, the influence of the commercial parking lot, office parking lot, residential parking lot, culture and sports parking lot, hospital parking lot, and mixed parking lot is 540 meters, 540 meters, 1080 meters, 792 meters, 432 meters, 504 meters respectively; second, investigated the variables data of the parking lot, and after finishing the survey data normalization processing, used SPSS to eliminate the correlation between indicators and establish a classification function; thirdly, through the function that can be seen, the nature of the parking lot, parking location, and number of parking spaces are positively related to the classification results, the public transit around the parking lot and the parking situation are negatively related to the classification results, the bus conditions affected the most significant, the impact of nature of the parking lot was not significant; and the last, this paper divided the area surrounding the parking lot into 5 classification and determined the threshold.

In this paper, due to the data acquisition is difficult, there are also some disadvantages, for example, sample size is not very enough and the results are not verified, about these problems, we will to do further research in the future.

\section{References}

[1] Song, H. (2008) Research on the Theory and Method of Definition for Traffic Impact Area. Master Thesis, Dalian Jiao tong University, Dalian.

[2] Wang, S.W., Sun, L.S. and Rong, J. (2013) Catchment Area Analysis of Beijing Transit Stations. Journal of Transportation Systems Engineering and Information Technology, No. 3, 183-188.

[3] Miao, L.X. and Liu, B. (1999) Land Use Patterns and Parking Planning for City CBD. City Planning Review, No. 23, 50-52, 63.

[4] Hang, R.Q. (2007) The Area Function and City Layout of Beijing. Journal of Capital University of Economics and Business, No. 9, 49-54.

[5] Meng, F.R. (2011) Functional Layout Planning Study for Urban Core Area of High-speed Railway Station. Master Thesis, Chang'an University, Chang'an.

[6] Wu, Y. (2010) An Urban Fringe Functions Research of Wuhan City.

[7] Chen, J., Wang, W. and He, B.H. (2006) Research on Classification for Urban Parking Lots of Public Buildings. Plan- 
ners, No. 22, 87-90.

[8] Ren, F.T, Liu, X.M. and Rong, J. (2007) Highway Capacity Manual (HCM 2000). China Communications Press, Beijing.

[9] Zhou, Z.H. and Wang, B. (2004) The Parking Demand Calculation Under Comprehensive Land Development. TranspoWorld, No. 11, 49-51, 20.

[10] Yin, J.J., He, Y.L. and Sun X.D. (2016) Effect Area Analysis of Beijing Parking Lot. Journal of Beijing University of Technology, No. 42, 433-439.

[11] Chen, Y.X., He, Y.L. Sun, X.D. and Ma, X.L. (2014) A Multi-Index Evaluation for the Level of Service of Sidewalks Based on the Clustering Method. Journal of Beijing University of Technology, No. 40, 549-554.

\section{Submit or recommend next manuscript to SCIRP and we will provide best service for you:}

Accepting pre-submission inquiries through Email, Facebook, LinkedIn, Twitter, etc.

A wide selection of journals (inclusive of 9 subjects, more than 200 journals)

Providing 24-hour high-quality service

User-friendly online submission system

Fair and swift peer-review system

Efficient typesetting and proofreading procedure

Display of the result of downloads and visits, as well as the number of cited articles

Maximum dissemination of your research work

Submit your manuscript at: http://papersubmission.scirp.org/ 